\title{
Bócio em bovinos ${ }^{1}$
}

\author{
Kamila P.F. Martins², Tânia R.S. Fonseca², Emanoelly S. Silva ${ }^{3}$, Thayanne C.P. Munhoz ${ }^{2}$, \\ Gustavo H.S. Dias ${ }^{3}$, Glauco J.N. Galiza ${ }^{4}$, Luiz G.S. Oliveira ${ }^{5}$ e Fabiana M. Boabaid ${ }^{5 *}$
}

\begin{abstract}
Martins K.P.F., Fonseca T.R.S., Silva E.S., Munhoz T.C.P., Dias G.H.S., Galiza G.J.N., Oliveira L.G.S. \& Boabaid F.M. 2018. [Goiter in cattle.] Bócio em bovinos. Pesquisa Veterinária Brasileira 38(6):1030-1037. Hospital Veterinário, Faculdade de Medicina Veterinária, Universidade de Cuiabá, Rua Itália s/n, Jardim Europa, Cuiabá, Mato Grosso, MT 78015-480, Brazil. E-mail: fabianaboabaid@hotmail.com

Goiter is a non-inflammatory and non-neoplastic enlargement of the thyroid gland in adults and neonates. One of the main causes involved is the nutritional deficiency of iodine. In this study three outbreaks of goiter in cattle are reported. In the first outbreak (Farm A) 60 calves were affected, of which 20 died soon after birth, 30 recovered and 10 remained sick. In the second outbreak (Farm B) a cow and its fetus were affected and in the third outbreak (Farm C) two calves were affected. The main clinical signs observed were bilaterally enlarged thyroid glands, weight loss, respiratory distress, hypotrichosis and myxedema. Additionally in the Farm A abortions were reported. Macroscopically the thyroid of the calves and fetus was enlarged, dark red with evident vascularization and cervical subcutaneous edema. In the Farm B the cow showed enlarged thyroid gland as well. Microscopically the calves and the fetus had hyperplastic and heterogeneous thyroid follicles with absence of colloid and vascularized interstitium. The thyroid of the cow was also hyperplastic, but had higher amount of colloid. In all outbreaks the mineral supplementation was performed by mixing non-iodized white salt with the mineral mixture. On the property $A$ the white salt was non-iodized and mixed in equal parts with the mineral salt. At property $B$ the salt was also mixed to a non-iodized white salt in ratio and 1:2, respectively. In the property $\mathrm{C}$, mineral salt and non-iodized white salt were offered in separate troughs in the field, and according to the owner's report the animals prioritized the consumption of white salt. In all the monitored properties it was recommended to stop the addition of white salt in the mineral mixture and the administration of iodine to the affected calves. After these measurements no new cases were observed in the properties. Despite being a well-known disease, there are still few reported cases of goiter in cattle in Brazil. Moreover, little is known about the actual mineral deficiencies of each region, and that simple nutritional management guidelines are still needed.
\end{abstract}

INDEX TERMS: Goiter, cattle, iodine deficiency, thyroid hyperplasia, ruminant diseases, Mato Grosso, Brazil, pathology, clinics.

\footnotetext{
${ }^{1}$ Recebido em 21 de maio de 2017.

Aceito para publicação em 28 de maio de 2017.

${ }^{2}$ Aluna de pós-graduação, Mestrado em Biociência Animal, Faculdade de Medicina Veterinária, Universidade de Cuiabá UNIC, Rua Itália s/n, Jardim Europa, Cuiabá, Mato Grosso, MT 78015-480, Brasil.

${ }^{3}$ Aluno de graduação, Faculdade de Medicina Veterinária, Universidade de Cuiabá UNIC, Rua Itália, s/n, Jardim Europa, Cuiabá, Mato Grosso, MT 78015-480.

${ }^{4}$ Laboratório de Patologia Animal, Centro de Saúde e Tecnologia Rural, Universidade Federal de Campina Grande UFCG, Avenida Universitária s/n, Bairro Santa Cecília, Patos, Paraíba, PB 58708-110, Brasil.

${ }^{5}$ Laboratório de Patologia Veterinária, Faculdade de Medicina Veterinária, Universidade de Cuiabá UNIC, Rua Itália s/n, Jardim Europa, Cuiabá, Mato Grosso, MT 78015-480.*Autor para correspondência: fabianaboabaid@hotmail.com
}

RESUMO.- Bócio é o aumento não inflamatório e não neoplásico da glândula tireoide em animais adultos e recém-nascidos. Uma das principais causas envolvidas é a deficiência nutricional de iodo. Relata-se neste trabalho, a ocorrência de três surtos de bócio em bovinos. Na primeira propriedade (Propriedade A), 60 bezerros foram afetados, sendo que 20 morreram logo após o nascimento, 30 recuperaram-se e 10 permaneceram doentes e tiveram remissão dos sinais apenas após tratamento parenteral com iodo. Na segunda propriedade (Propriedade B) uma vaca e seu feto foram acometidos e na terceira (Propriedade C) dois bezerros foram afetados. Os principais sinais clínicos 
observados nos bezerros foram aumento de volume bilateral na região cervical ventral, emagrecimento, dificuldade respiratória, hipotricose e desenvolvimento corpóreo retardado. Na propriedade A foi relatada ainda a ocorrência de abortamentos. Macroscopicamente, os bezerros e o feto apresentavam tireoide aumentada, vermelho-escura, com vascularização evidente e edema subcutâneo cervical. No surto dois também foi observado, à necropsia, aumento de volume da glândula tireoide da vaca. Microscopicamente, a tiroide dos bezerros e do feto apresentava folículos tireoidianos hiperplásicos, heterogêneos, destituídos de coloide e com interstício acentuadamente vascularizado. A tireoide da vaca era semelhante à dos bezerros, no entanto, possuía quantidade maior de coloide. Em todos os casos a suplementação mineral era realizada por meio da mistura de sal mineral com sal branco. Na Propriedade A o sal branco era não iodado e misturado em partes iguais com o sal mineral. Na Propriedade B o sal também era misturado a um sal branco não iodado na proporção e 1:2, respectivamente. Na Propriedade C o sal mineral e o sal branco não iodado eram ofertados em cochos separados no campo e, segundo relato do proprietário, os animais priorizavam o consumo do sal branco. Em todas as propriedades acompanhadas foi recomendada a interrupção da adição de sal branco na mistura mineral e a administração de iodo aos bezerros acometidos. Após essas medidas não foram observados novos casos nas propriedades. Apesar de ser uma enfermidade bem conhecida, ainda são poucos os relatados de casos de bócios em bovinos no Brasil. Além disso, pouco se sabe sobre as reais deficiências minerais de cada região, e que simples orientações de manejo nutricional ainda são necessárias.

TERMOS DE INDEXAÇÃO: Bócio, bovinos, deficiência de iodo, hiperplasia da tireoide, doenças de ruminantes, Mato Grosso, patologia, clínica.

\section{INTRODUÇ̃̃o}

A produção normal de hormônios tireoidianos triiodotironina (T3) e tiroxina (T4), essenciais para a reprodução e para o desenvolvimento normal dos animais (Frankson et al. 2011), é dependente de duas moléculas, a tirosina e o iodo. 0 iodo torna-se disponível somente após sua ingestão através da alimentação e conversão em iodeto no trato gastrointestinal. Conforme são produzidos, os hormônios T3 e T4 são armazenados como coloide nos ácinos formados pelas células foliculares. A atividade basal reduzida desses hormônios, pela ausência de iodo disponível ou pela impossibilidade de sua utilização, gera uma hiperestimulação tireoidiana por hormônio tireoestimulante (TSH) e consequente formação do bócio (Cunningham \& Klein 2008, Eiler 2012).

Bócio é uma manifestação clínica que consiste no aumento de volume da glândula tireoide sem o envolvimento de um processo neoplásico ou inflamatório (Capen 1993). Essa hiperplasia, pelo baixo nível de iodo na circulação sanguínea, pode ocorrer pela deficiência do mineral na alimentação, pela ingestão de substâncias bociogênicas presentes em plantas ou silagem à base de soja, pela deficiência de selênio, que impossibilita a conversão de T4 em T3, ou por um elevado nível de cálcio na dieta, o que diminui a absorção do iodo no intestino (Hemken et al. 1971, Wichtel et al. 1996, Riet-Correa 2007, Tokarnia et al. 2010).
A deficiência de iodo em vacas gestantes pode ocasionar bócio congênito, que se caracteriza pelo nascimento de bezerros com aumento de volume da glândula tireoide. Casos já foram descritos principalmente em bovinos, caprinos, ovinos e humanos (Wither 1997, Pezzuti et al. 2009, Campbell et al. 2012, Panziera et al. 2014). Os animais com bócio congênito podem apresentar um crescimento deficiente, anorexia, mixedema, intolerância ao frio, pele espessa com áreas de alopecia, hiperpigmentação e pelos quebradiços (Radostits et al. 2002, Tokarnia et al. 2010).

Em animais adultos, os efeitos dos baixos níveis de iodo na alimentação são, na maioria das vezes, subclínicos. Quando há manifestação de sinais, esses são relacionados sobretudo à reprodução, como diminuição da libido em machos, abortamentos, partos distócicos, ou ainda associados à queda na produção de leite (Mohan Reddi \& Rajan 1986, Thrift et al. 1999a, 1999b, Kumar et al. 2014, Randhawa et al. 2014).

0 excesso de iodo também é descrito como causa de bócio em animais, pois interfere com a fusão dos lisossomos às gotículas de coloide internalizadas pelas células foliculares, impedindo a síntese e secreção de T3 e T4, e, dessa forma, estimulando a liberação de TSH (Blaxter 1948, Fish \& Swanson 1982, La Perle 2013, Ong et al. 2014, Rosol \& Gröne 2016). É sabido, por exemplo, que potros nascidos de éguas alimentadas com algas marinhas, as quais contêm teores elevados de iodo, ou ainda que animais criados em ambientes com alta disponibilidade do mineral podem desenvolver bócio devido ao aumento dos níveis séricos de iodo (Durham 1995, Paulíková et al. 2002, Rosol \& Gröne 2016). Para que haja manifestação clínica de bócio associado a excesso de iodo, é necessário que sejam administradas doses diárias muito além daquelas previstas para a espécie e categoria animal. Fetos e neonatos também são considerados grupos de risco para a apresentação clínica do excesso de iodo, pois esse mineral é concentrado tanto pela placenta como pela glândula mamária (Seimiya et al. 1991, Durham 1995, Rosol \& Gröne 2016).

Há ainda o bócio congênito de caráter hereditário, também denominado bócio disormonogênico hereditário, no qual ocorrem mutações em genes que codificam enzimas envolvidas com a síntese dos hormônios tireoidianos. Os genes associados a essa condição parecem ser autossômicos de expressão recessiva, havendo registros em bovinos da raça Afrikander, ovinos Corriedale, Merino, Romney Marsh e Dorset Horn, além de caprinos Saanen miniaturas (Robbins et al. 1966, De Vijlder et al. 1981, Vaisman et al. 2004).

No Brasil, os relatos de bócio congênito por deficiência de iodo em bovinos são escassos, havendo registros nos estados de Minas Gerais, Mato Grosso, Mato Grosso do Sul e Goiás (Tokarnia et al. 2000, 2010). A infrequência desses casos fica evidente ao serem analisados os dados de estudos de defeitos congênitos na espécie bovina no Brasil. Em levantamentos de registros de necropsia obtidos de diferentes laboratórios de patologia na região sul do Brasil (Pavarini et al. 2008, Marcolongo-Pereira et al. 2010, Macêdo et al. 2011), um do semiárido nordestino (Dantas et al. 2010) e outro da região norte (Campos et al. 2009) apenas um caso de bócio congênito em feto bovino foi registrado (Macêdo et al. 2011). 0 objetivo desse trabalho é relatar a ocorrência de bócio em bovinos no Estado do Mato Grosso, Brasil, abordando os aspectos epidemiológicos, clínicos e patológicos dessa enfermidade. 


\section{MATERIAL E MÉTODOS}

Os dados epidemiológicos e clínicos foram obtidos em entrevistas com proprietários, veterinários responsáveis e durante visitas às propriedades onde os casos ocorreram. Realizou-se necropsia de três bezerros, sendo um de cada propriedade, e de uma vaca, da segunda propriedade. Todos os bovinos submetidos à necropsia tiveram morte natural e, durante o exame de necropsia, fragmentos de diversos órgãos das cavidades abdominal e torácica, sistema nervoso central, pele e glândula tireoide foram coletados, fixados em formol tamponado a $10 \%$, processados rotineiramente para histologia e corados pela técnica de hematoxilina e eosina (HE).

\section{RESULTADOS}

\section{Epidemiologia e sinais clínicos}

0 primeiro caso ocorreu no período de janeiro a abril de 2015, em uma propriedade rural do município de Nossa Senhora


mato-grossense (Propriedade A). Neste estabelecimento havia 122 bovinos destinados à produção de leite e corte, divididos em lotes de vacas solteiras e lactantes e representados pelas raças Girolando (40), Holandês (10), Nelore (20), Jersey (5) e mestiços (47). Os bovinos eram mantidos em piquetes formados, predominantemente, por Brachiaria brizantha, com menores proporções de B. humidicola, Andropogon gayanus e Panicum maximum cv. Massai. A água fornecida era proveniente de poço e a suplementação mineral era realizada com partes iguais de sal branco não iodado, misturado a sal mineral comercial. A mistura era fornecida em cochos distribuídos em todos os piquetes da propriedade. A reprodução era através de monta natural e os bezerros acometidos não eram filhos do mesmo touro. 0 proprietário relatou que alguns dos bezerros acometidos eram filhos de vacas que foram introduzidas na propriedade no início da prenhez. Segundo responsável pela propriedade, a condição já era registada pelo segundo ano consecutivo, sendo que entre os 80 bezerros nascidos na última temporada, de ambos os sexos e diferentes raças, 20 vieram a óbito logo após o nascimento apresentando aumento de volume da região cervical ventral. Dos bezerros que apresentaram os sinais clínicos ao nascimento, cerca de 30 se recuperaram espontaneamente e 10 apresentaram regressão do volume cervical apenas após tratamento com iodo parenteral. As manifestações clínicas observadas nos bezerros compreendiam aumento de volume bilateral na região cervical ventral, caudal ao ângulo das mandíbulas (Fig.1). Além disso, parte dos bezerros possuía áreas de rarefação pilosa (hipotricose) e mixedema, principalmente na face e região cervical. Alguns animais apresentavam relutância em se movimentar, passavam boa parte do tempo em decúbito esternal e respondiam pouco aos estímulos externos. Nos animais adultos não foram observados aumento de volume da tireoide. Apesar de não haver estimativas numéricas da ocorrência de abortamentos, segundo o proprietário, esses foram observados principalmente no terço final da gestação, com fetos apresentando hipotricose e aumento de volume na região laríngea. Por ocasião do surto foi realizada a necropsia de um bezerro macho, de um dia de vida e sem raça definida.

0 segundo caso ocorreu em abril de 2016 em uma propriedade na área rural da cidade de Várzea Grande (15³8'49"S 5607'58"0) (Propriedade B). No local eram criadas três vacas Girolanda e um touro Nelore mantidos em piquetes com pastagem degradada e água à vontade. No período da seca, entre maio e setembro, os bovinos recebiam casquinha de soja e cevada. Durante o ano todo recebiam ainda suplementação mineral no cocho, que era composta por duas partes de sal branco não iodado e uma parte de sal mineral comercial. 0 manejo reprodutivo era através de monta natural. A proprietária informou que no ano anterior dois bezerros nasceram letárgicos, proporcionalmente pequenos e morreram poucas horas após o nascimento, mas

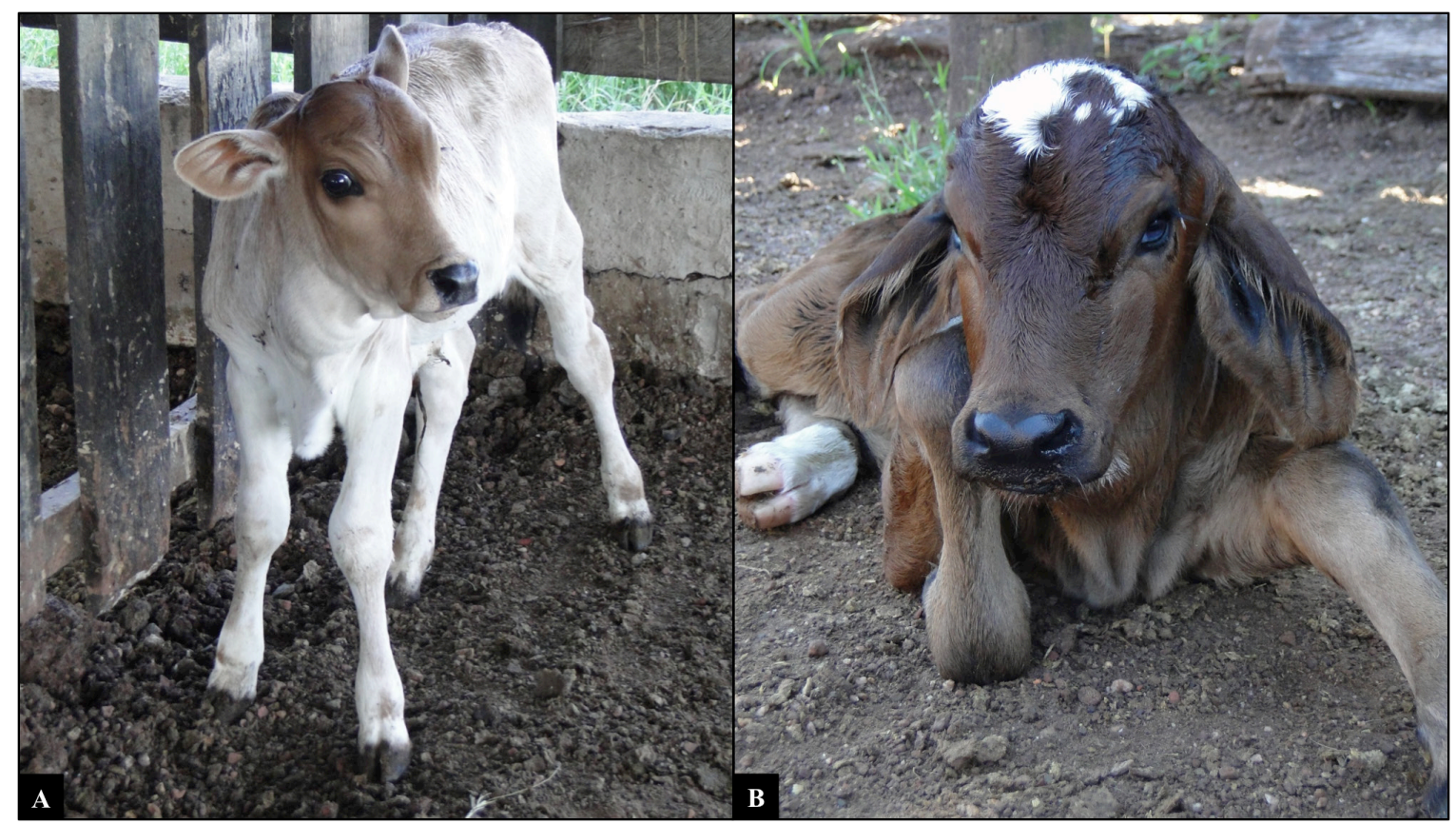

Fig.1. Bócio em bovinos no Estado de Mato, Grosso. (A,B) Bezerros da Propriedade A em que se evidencia aumento bilateral de volume na região cervical ventral. 
não soube dizer se os bezerros possuíam aumento de volume submandibular. Em visita à propriedade foi realizada a necropsia de uma vaca, no terço final da gestação que apresentara prostração, anorexia, decúbito esternal e finalmente lateral e morte em um curso de 12 horas.

0 terceiro caso foi registrado em uma propriedade no município de Jaciara (1557'54”S 5458’04”0) (Propriedade C). No local eram criados 96 bovinos das raças Nelore, Girolanda, Gir e mestiços. A reprodução era realizada através de monta natural com um touro Girolando e inseminação artificial. Os bovinos eram mantidos em pastagem de Brachiaria brizantha com fornecimento de sal branco não iodado em cocho separado do sal mineral. Segundo o proprietário, o consumo dos bovinos era de aproximadamente quatro sacos de sal branco não iodado para cada um saco de sal mineral. Na história clínica o responsável pelo animal relatou que o mesmo possuía dificuldades para mamare que apresentava um aumento de volume submandibular. Um mês depois, o produtor relatou que mais um bezerro apresentou aumento de volume discreto da tireoide e se recuperou algumas semanas após a suplementação mineral. Nesta propriedade um bezerro Gir, com oito dias de idade, morreu e foi encaminhado para o exame de necropsia.

\section{Achados macroscópicos}

Macroscopicamente observou-se, nos bezerros das Propriedades A e C, bom estado corporal, acentuado aumento de volume na região cervical ventral, imediatamente caudal ao ângulo das mandíbulas. Ao rebater a pele, evidenciou-se que a glândula tireoide estava difusamente aumentada, vermelho-escura e com a vascularização evidente. 0 bezerro da Propriedade A apresentava ainda moderado edema subcutâneo na região da cabeça, pescoço e barbela (mixedema).

A vaca da Propriedade B apresentava estado corporal ruim. À necropsia constatou-se fígado difusamente amarelado, de bordos arredondados e aspecto untuoso. A tireoide estava difusa e discretamente aumentada e de coloração vermelha. Essa alteração era, entretanto, imperceptível ao exame externo, sendo constatada somente após a remoção da pele da região cervical. Ao examinar o feto desta vaca, observou-se que este já estava a termo, entretanto ele apresentava áreas bilaterais, multifocais extensas de alopecia e hipotricose. Notou-se ainda que a tireoide estava acentuadamente aumentada e com caraterísticas semelhantes às dos bezerros das outras propriedades (Fig.2).

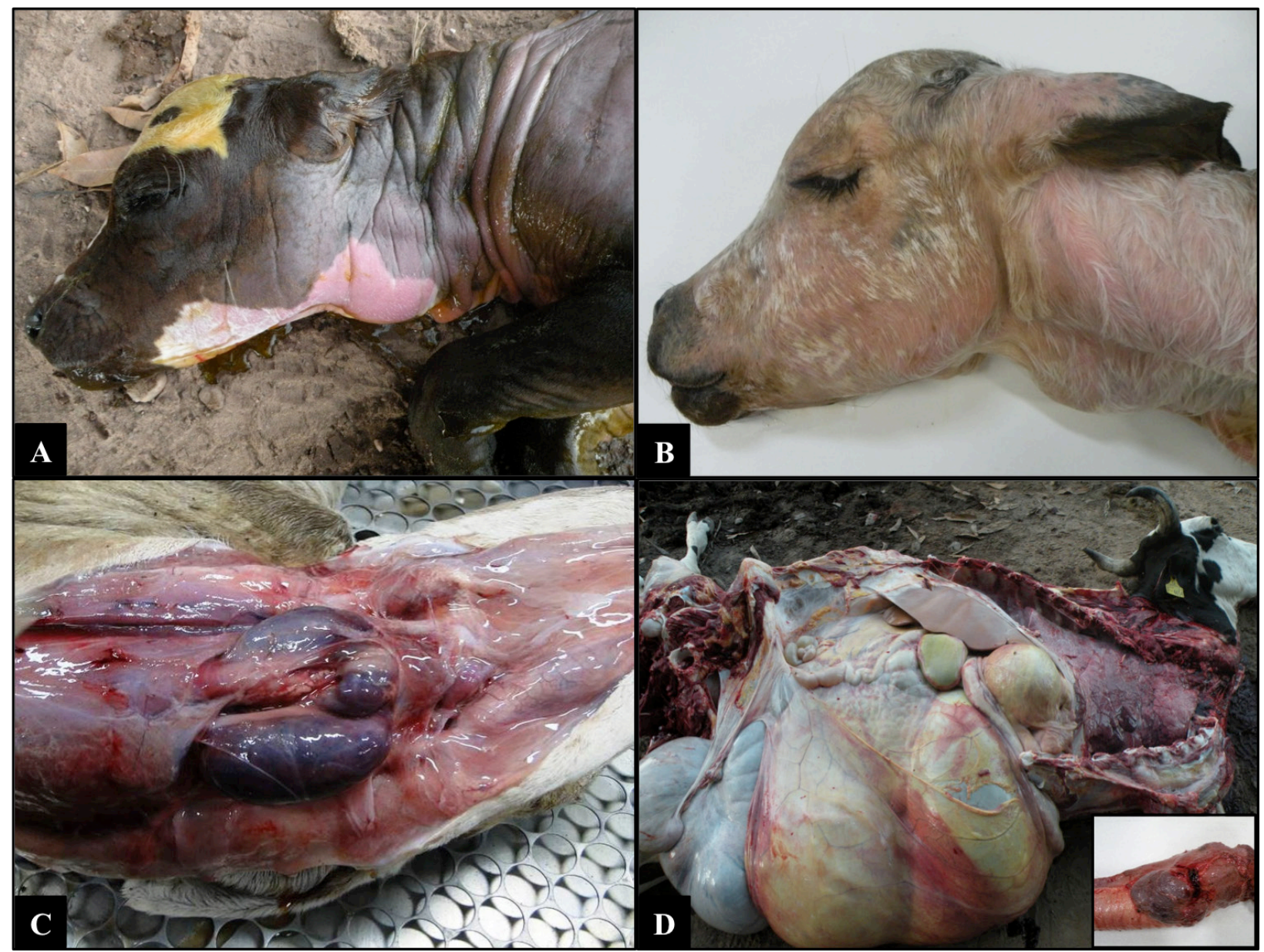

Fig.2. Bócio em bovinos no Estado de Mato Grosso. (A) Feto a termo da Propriedade B com bócio congênito, no qual se observa aumento de volume acentuado na região cervical ventral e áreas extensas de alopecia. (B) Bezerro da Propriedade $\mathrm{C}$ com oito dias de idade, em que se visualiza aumento de volume na região cervical ventral. (C) Bezerro da Propriedade A com tireoide difusamente aumentada e avermelhada, com mixedema do tecido subcutâneo da região submandibular e cervical ventral. (D) Vaca da Propriedade B no terço final da gestação e com fígado difusamente amarelado. Em destaque a região laríngea da vaca demonstrando a tireoide discretamente aumentada. 


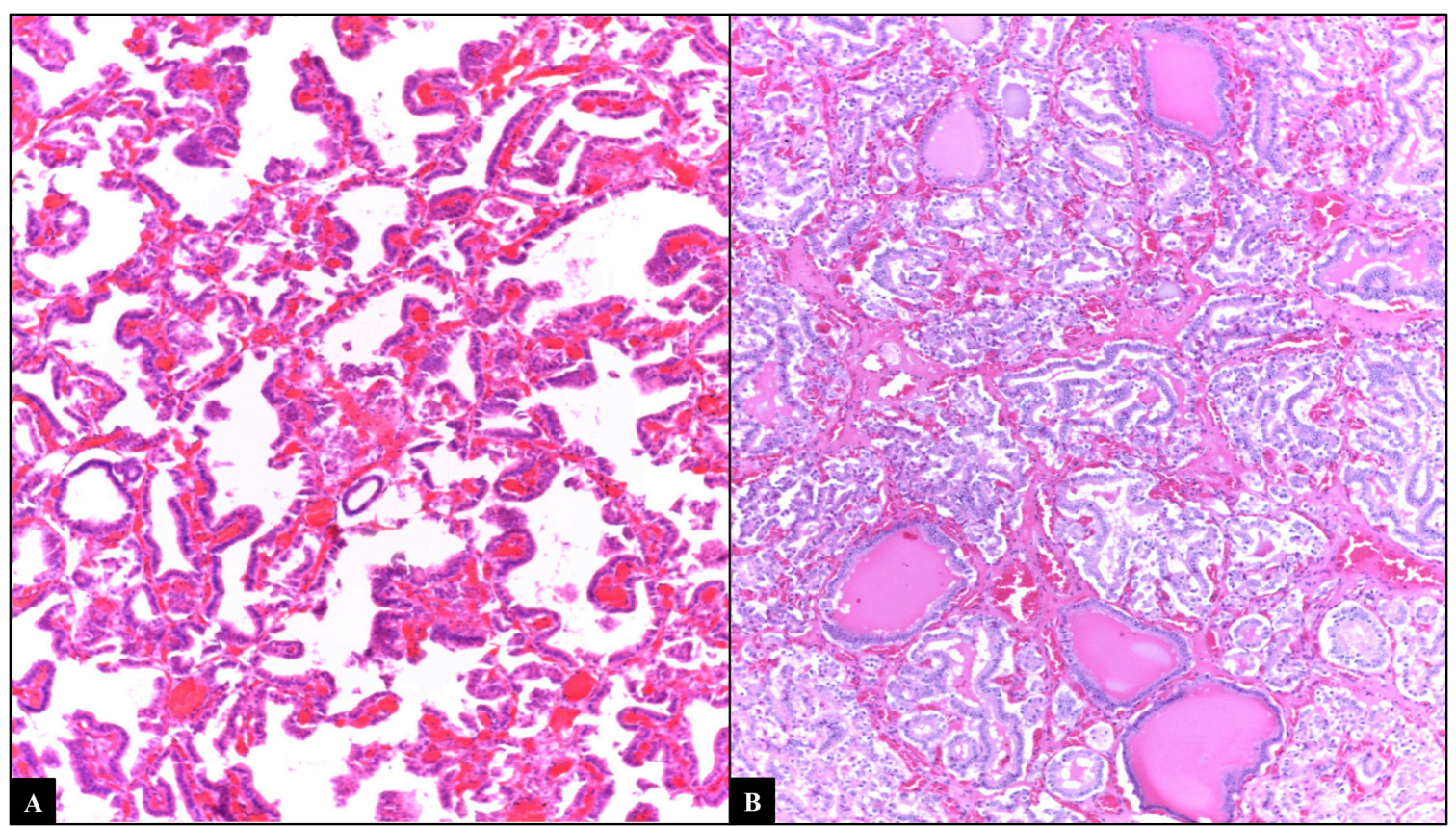

Fig.3. Bócio em bovinos no Estado de Mato Grosso. (A) Tireoide, feto da Propriedade B, os folículos apresentam-se hiplerplásicos, com múltiplas projeções papilares para a luz folicular destituída de coloide e com interstício amplamente vascularizado (bócio hiperplásico difuso). HE, obj.4x. (B) Tireoide da vaca da Propriedade B, demonstrando hiperplasia moderada dos folículos tireoidianos com ocasionais folículos contendo escasso coloide intraluminal. HE, obj.4x.

\section{Achados microscópicos}

$\mathrm{Na}$ análise histológica dos dois bezerros e do feto submetidos à necropsia, a principal alteração foi constatada na tireoide, a qual apresentava um aumento difuso no número de células foliculares (hiperplasia). Os folículos eram destituídos de coloide, tortuosos, possuíam diferentes tamanhos, com uma a três camadas de células foliculares e frequentemente formavam projeções papilares. As células foliculares eram cuboidais a colunares, com citoplasma marcadamente eosinofílico e núcleo hipercromático. 0 tecido intersticial estava amplamente vascularizado. A tireoide da vaca também possuía folículos heterogêneos e com moderada hiperplasia, com características celulares semelhantes a dos bezerros, porém era notado coloide no interior de ocasionais folículos (Fig.3).

Na pele do bezerro da Propriedade A se observou espessamento da derme com afrouxamento das fibras de colágeno e discreta deposição de material de aspecto mucinoso em matriz conjuntiva. A pele do feto apresentava ocasionais folículos pilosos em fase telógena, predominantemente sem as hastes pilosas. 0 infundíbulo folicular demonstrava moderado espessamento que, por vezes, se afilava e formava um cordão extenso.

No fígado da vaca observou-se vacuolização hepatocelular multifocal moderada, caracterizada pela formação de vacúolos claros, grandes e bem definidos no interior do citoplasma dos hepatócitos, deslocando frequentemente o núcleo para a periferia.

\section{DISCUSSÃO}

Os casos de bócio em bovinos descritos nesse trabalho foram diagnosticados com base nos achados clínico-patológicos, associados aos dados epidemiológicos. Além disso, com o diagnóstico de bócio, os produtores foram orientados a cessar o uso de sal branco e utilizar apenas a mistura mineral. Após a mudança de manejo, não se observaram novos casos em nenhuma das propriedades, e os bezerros da Propriedade A apresentaram regressão da hiperplasia tireoidiana, o que reforça a teoria da carência de iodo na patogenia da enfermidade.

No Brasil o bócio é, na maior parte das vezes, derivado da deficiência nutricional de iodo (Martins 1946, Tokarnia et al. 2000, Panziera et al. 2014). As doenças decorrentes das deficiências minerais em ruminantes estão relacionadas com a área geográfica, com a qualidade das pastagens e com a ausência de suplementação mineral. Entretanto, é possível constatar que, mesmo antes da utilização do sal iodado nas misturas minerais, os casos de bócio em bovinos eram considerados infrequentes, provavelmente devido ao fato de que os bovinos necessitam de uma quantidade menor de iodo quando comparados aos seres humanos, ou ainda porque adquirem o mineral através de outras fontes, como a água e as pastagens (Tokarnia et al. 2000, 2010).

Nas três propriedades acompanhadas constatou-se o uso de sal mineral próprio para bovinos, com quantidades adequadas de iodo para a espécie, no entanto, a administração do sal branco não iodado misturado ao sal mineral, fez com que os níveis de iodo se diluíssem e se tornassem insuficientes. Outros autores já alertavam sobre o risco da indução de bócio, em decorrência da utilização de sal grosso não iodado como base para incorporação da mistura mineral (Peixoto et al. 2003). Além disso, é importante ressaltar que o cloreto de sódio pode agir tanto como estimulante da ingestão da suplementação mineral, quanto como limitador de seu consumo quando em excesso (Peixoto et al. 2005). Nas propriedades investigadas, a proporção de mistura de cloreto de sódio tornou-se limitante de consumo de mistura mineral e pode ter influenciado negativamente a ingestão de iodo. 
Somado ao manejo nutricional inadequado, com adição de cloreto de sódio à mistura mineral, há ainda indícios de que a carência de iodo seja um problema inerente ao solo do Estado de Mato Grosso (Tokarnia et al. 2010). Como regra geral, a dispersão do iodo para o solo ocorre principalmente através da volatilização do mineral presente no mar até a atmosfera e, portanto, quanto mais distante a área estiver do mar, menor a quantidade de iodo no solo (Fuge 2013). O Estado de Mato Grosso, localizado no centro da América do Sul, representa o ponto mais distante dos oceanos de todo o continente, o que poderia contribuir para a deficiência de iodo em seu solo.

Fêmeas em terço final de gestação e de raças leiteiras necessitam de um maior equilíbrio metabólico para a transição do período do parto até a preparação da glândula mamária para a produção de leite. A glândula tireoide desempenha papel importante nessa fase, pois ao secretar tiroxina (T4), estimula o metabolismo energético do animal. Quando há deficiência de iodo e consequente queda nos níveis séricos de T4, as vacas passam a mobilizar gordura para produção de energia (Djokovic et al. 2014, Fiore et al. 2015). A vaca da propriedade B passava por esse período de transição, com um feto a termo e em déficit energético. 0 papel dos hormônios tireoidianos no metabolismo energético aponta a deficiência de iodo como causa mais provável do bócio, bem como da lipidose hepática constatados nessa vaca. Conforme relatado previamente, cetose pode ser desencadeada por hipotireoidismo em vacas, e a suplementação com iodo pode diminuir a incidência desse distúrbio metabólico (Hemken 1970).

0 acometimento de adultos por bócio é raro e, quando há deficiência de iodo no rebanho, as manifestações normalmente se restringem a perturbações de fertilidade ou são subclínicas (Tokarnia et al. 2010, Randhawa et al. 2014). Entretanto, em fetos a termo a condição é de especial importância, pois no terço final da gestação, o requerimento de iodo fetal é superior ao do bovino adulto e este deve ser obtido a partir do plasma materno (Hemken 1970).

Apesar de não mensuradas estatisticamente, a queixa de perdas reprodutivas do produtor da propriedade A é condizente com a deficiência de iodo. Tanto em machos quanto em fêmeas as alterações no sistema reprodutor podem levar à infertilidade e abortamentos devido à participação direta de T3 e T4 no funcionamento das gônadas. Nas fêmeas, essas enzimas estimulam a esteroidogênese ovariana para que haja a liberação dos hormônios necessários à ovulação e posterior manutenção da prenhez (Thrift et al. 1999a, 1999b, Spicer et al. 2001). Nos machos o hipotireoidismo está associado à diminuição do volume, concentração e motilidade espermática, já que os níveis séricos de T4 determinam a atividade das células de Sertoli (Mohan Reddi \& Rajan 1986, Oluwole et al. 2013).

Alguns minerais são capazes de interferir no funcionamento normal da tireoide, a exemplo do cálcio, que quando apresenta níveis séricos elevados, pode diminuir a absorção de iodo no intestino e favorecer o desenvolvimento de bócio (Hellwig 1940, Taylor 1954). De maneira inversa, a deficiência de selênio propicia a ocorrência de bócio, pois está estreitamente relacionado com a formação de enzimas que convertem T4 em T3 (Levander \& Whanger 1996). O nitrato, encontrado na água, forragens e solo, principalmente em áreas com fertilização constante do solo, também pode participar da patogênese do bócio. Apesar do mecanismo ainda não ser precisamente esclarecido, sabe-se que quando em excesso, o nitrato compete com o iodo e o impede de entrar na glândula tireoide (Eskiocak et al. 2005). Acredita-se que, nos casos de bócio aqui relatados, não houve envolvimento e interferência de nenhum desses minerais, já que após a suplementação de iodo nas três propriedades não foram registrados novos casos.

Plantas que contêm glicosídeos cianogênicos, como as do gênero Manihot, podem induzir bócio pela formação hepática de tiocianeto, que impede a absorção de iodo pela tireoide. Entretanto, a maioria das intoxicações por plantas que contêm ácido cianídrico são agudas e letais, enquanto que o desenvolvimento de bócio só ocorre quando há ingestão de doses baixas por um longo tempo (Amorim et al. 2005, Tokarnia et al. 2012). Outras plantas com ação bociogênica são as crucíferas (couve, repolho, brócolis) e a soja, que impedem a formação de tiroxina (Ikeda et al. 2000, Tokarnia et al. 2010). Na propriedade B a produtora relatou oferecer casquinha de soja para os animais durante a seca, porém, no período em que a visita foi realizada, a vaca só se alimentava a pasto e recebia mistura mineral com sal branco não iodado. Nas demais propriedades não se constataram o uso ou disponibilidade de planta bociogênica.

A possibilidade de o bócio congênito ser oriundo de defeitos genéticos foi descartada, visto que as Propriedades A e C faziam manejo reprodutivo com diferentes touros e mesmo na Propriedade B, apesar da existência de um único reprodutor, não se registrou reincidência dessa condição após a troca da suplementação mineral.

Embora casos de bócio congênito por carência de iodo sejam responsivos à suplementação desse mineral, casos relacionados com outras etiologias, como a competição de certos minerais pela absorção entérica de iodo, os defeitos genéticos na função tireoidiana ou a ingestão de substâncias bociogênicas, a terapia mais indicada é a administração parenteral de tiroxina (T4) (Singh \& Beigh 2013, Kashyap et al. 2015).

Os sinais clínicos e os achados macroscópicos encontrados nos casos apresentados são semelhantes aos observados em outras descrições de bócio por deficiência de iodo em bovinos (Wither 1997, Tokarnia et al. 2000) bem como em caprinos (Martins 1946, Panziera et al. 2014), ovinos (Campbell et al. 2012) e seres humanos (Pezzuti et al. 2009). Em bezerros, o aumento bilateral difuso da tireoide é considerado o principal indicador do hipotireoidismo congênito (Stukovsky et al. 1961, Wither 1997). O aumento de volume das tireoides é apontado como a causa da maioria dos óbitos dos bezerros neonatos da Propriedades A, decorrente da dificuldade em realizar a mamada e, consequente, debilidade geral, semelhante ao que foi constatado em outros relatos (Sinclair \& Andrews 1954, Seimiya et al. 1991).

As características histológicas descritas em todos os bezerros são compatíveis com bócio hiperplásico difuso. As células foliculares são mais numerosas e os ácinos formados, na maioria das vezes não apresentam coloide. A ausência de coloide é marcante, já que as células foliculares estimuladas continuamente pelo TSH tornam-se colunares para exercer maior captação de coloide por endocitose (Capen 1993, Jones et al. 2000, Almeida et al. 2013, La Perle 2013). A pele, por sua vez, apresentou à histologia, folículos em fase telógena sem hastes pilosas ou ainda folículos displásicos. Essas 
características são consideradas indicativas de um distúrbio folicular de origem endócrina (Gross et al. 2009).

Na fêmea adulta da Propriedade B, a análise histológica da tireoide evidenciou hiperplasia das células foliculares com quantidade variada de coloide. Em jovens, quando essa característica é observada, remete a uma fase de regressão do bócio hiperplásico após suplementação de iodo. Em adultos o bócio se manifesta de forma menos evidente, pois com o aumento da idade há uma diminuição na demanda por hormônios tireoidianos (La Perle 2013) o que justifica o aumento bilateral difuso da tireoide da vaca não apresentar a mesma intensidade que no feto.

Casos de bócio congênito como os descritos, evidenciam que apesar do aumento da utilização de misturas minerais, orientações simples de manejo nutricional ainda se fazem necessárias. Sendo assim, torna-se evidente que a assistência de profissionais capacitados no campo é uma das premissas para a prevenção de doenças carenciais nos rebanhos brasileiros.

\section{CONCLUSÕES}

O diagnóstico de bócio por deficiência de iodo em bovinos foi estabelecido com base nos aspectos epidemiológicos, clínico-patológicos e resposta à suplementação de iodo.

Conclui-se que o bócio afeta principalmente fêmeas prenhes, sendo responsável por perdas econômicas associadas a abortamentos e nascimento de animais fracos e subdesenvolvidos.

Agradecimentos.- À Coordenação de Aperfeiçoamento de Pessoal de Nível Superior (CAPES) pela concessão de bolsa de estudo.

\section{REFERÊNCIAS}

Almeida O., Carolina A., Arenales Torres A.A., Borges I.L., Simone Souza F., Luvizzoto R., Rozza M.A. \& Bernadete D. 2013. Bócio hiperplásico difuso em caprino recém-nascido, relato de caso. Arch. Vet. Sci. 18(3):32-33.

Amorim S.L., Medeiros R.M.T. \& Riet-Correa F. 2005. Intoxicação experimental por Manihot glaziovii (Euphorbiaceae) em caprinos. Pesq. Vet. Bras. 25(3):179-187. http://dx.doi.org/10.1590/S0100-736X2005000300009.

Blaxter K.L. 1948. Severe experimental hyperthyroidism in the ruminant. II. Physiological effects. J. Agr. Sci. 38(1):20-27. http://dx.doi.org/10.1017/ S0021859600005104.

Campbell A.J.D., Croser E.L., Milne M.E., Hodge P.J. \& Webb Ware J.K. 2012. An outbreak of severe iodine-deficiency goiter in a sheep flock in north-east Victoria. Aust. Vet. J. 90(6):235-239. http://dx.doi.org/10.1111/j.17510813.2012.00915.x. PMid:22632287.

Campos K.F., Sousa M.G.S., Silva N.S., Oliveira C.H.S., Duarte M.D., Barbosa J.D. \& Oliveira C.M.C. 2009. Doenças congênitas em bovinos diagnosticadas pela Central de diagnóstico Veterinário (Cedivet) da Universidade Federal do Pará, no período de 1999 a 2009. Anais VIII Congresso Brasileiro de Buiatria. Ciênc. Anim. Bras. 1(Supl.):13-18.

Capen C.C. 1993. The endocrine glands, p.315-316. In: Jubb K.V.F., Kennedy P.C. \& Palmer N.C. (Eds), Pathology of Domestic Animals. 4th ed. Vol.3. Academic Press, San Diego. http://dx.doi.org/10.1016/B978-0-12-391607-5.50011-X.

Cunningham J.G. \& Klein B.G. 2008. Glândulas endócrinas e suas funções, p.432-438. In: Ibid. (Eds), Tratado de Fisiologia Veterinária. 4⿳a ed. Elsevier, Rio de Janeiro.

Dantas A.F.M., Riet-Correa F., Medeiros R.M.T., Galiza G.J.N., Pimentel L.A., Anjos B.L. \& Mota R.A. 2010. Malformações congênitas em ruminantes no semiárido do nordeste brasileiro. Pesq. Vet. Bras. 30(10):807-815. http:// dx.doi.org/10.1590/S0100-736X2010001000002. de Vijlder J.J., van Ommen G.J., van Voorthuizen W.F., Koch C.A., Arnberg A.C., Vassart G., Dinsart C. \& Flavell R.A. 1981. Nonfunctional thyroglobulin messenger RNA in goats with hereditary congenital goiter. J. Mol. Appl. Genet. 1(1):51-59. PMid:6125553.

Djokovic R., Cincovic M., Kurcubic V., Ptrovic M., Lalovic M., Jasovic B. \& Stanimirovic Z. 2014. Endocrine and metabolic status of dairy cows during transition period. Thai J. Vet. Med. 44(1):59-66.

Durham A.E. 1995. Congenital goitre in two colt foals born to mares fed excesso iodine during pregnancy. Equine Vet. Educ. 7(5):239-241. http:// dx.doi.org/10.1111/j.2042-3292.1995.tb01236.x.

Eiler H. 2012. Glândulas endócrinas, p.602-605. In: Reece W.O. (Ed.), Dukes: fisiologia dos animais domésticos. $12^{a}$ ed. Guanabara Koogan, Rio de Janeiro.

Eskiocak S., Dundar C., Basoglu T. \& Altaner S. 2005. The effects of taking chronic nitrate by drinking water on thyroid functions and morphology. Clin. Exp. Med. 5(2):66-71. http://dx.doi.org/10.1007/s10238-005-00681. PMid: 16096856.

Fiore E., Piccione G., Gianesella M., Praticò V., Vazzana I., Dara S. \& Morgante M. 2015. Serum thyroid hormone evaluation during transition periods in dairy cows. Arch. Anim. Breed. 58(2):403-406. http://dx.doi.org/10.5194/ aab-58-403-2015.

Fish R.E. \& Swanson E.W. 1982. Effects of excessive intakes of iodine upon growth and thyroid function of growing holteins heifers. J. Dairy Sci. 65(4):605-610. http://dx.doi.org/10.3168/jds.S0022-0302(82)82237-6. PMid:7096725.

Frankson R.D., Wilke W.L. \& Fails A.D. 2011. Endocrinologia, p.173-174. In: Ibid (Eds), Anatomia e fisiologia dos animais de fazenda. $7 \stackrel{\text { a }}{\text { ed. Guanabara }}$ Koogan, Rio de Janeiro.

Fuge R. 2013. Soils and iodine deficiency, p.417-432. In: Sellinus 0., Alloway B., Centeno J.A., Finkelman J.B., Fuge R., Lindh U. \& Smedley P. (Eds), Essentials of Medical Geology. Spinger, Netherland. http://dx.doi.org/10.1007/97894-007-4375-5 17.

Gross T.L., Ihrke P.J., Walder E.J. \& Affolter V.K. 2009. Doenças atróficas dos anexos, p.465-468. In: Ibid. (Eds), Doenças de Pele do Cão e do Gato: diagnóstico clínico e histopatológico. $2^{\underline{a}}$ ed. Roca, São Paulo.

Hellwig C.A. 1940. Experimental goiter due to calcium. Arch. Surg. 40(1):98102. http://dx.doi.org/10.1001/archsurg.1940.04080010101011.

Hemken R.W. 1970. Iodine. J. Dairy Sci. 53(8):1138-1143. http://dx.doi. org/10.3168/jds.S0022-0302(70)86357-3. PMid:4918953.

Hemken R.W., Vandersall J.H., Sass B.A. \& Hibbs J.W. 1971. Goitrogenic effects of a corn silage-soybean meal supplemented ration. J. Dairy Sci. 54(1):85-88. http://dx.doi.org/10.3168/jds.S0022-0302(71)85782-X. PMid:5102140.

Ikeda T., Nishikawa A., Imazawa T., Kimura S. \& Hirose S. 2000. Dramatic synergism between excess soybean intake and iodine deficiency on the development of rat thyroid hyperplasia. Carcinogenesis 21(4):707-713. http://dx.doi.org/10.1093/carcin/21.4.707. PMid:10753207.

Jones T.C., Hunt R.D. \& King N.W. 2000. Glândulas endócrinas, p.1245-1259. In: Ibid. (Eds), Patologia Veterinária. 6a ed. Manole, São Paulo.

Kashyap D.K., Giri D.K. \& Dewangan G. 2015. Therapeutic management of goiter in calves. Intas Polivet 16(1):88-89.

Kumar A., Gupta K. \& Bhat G.R. 2014. Caesarean section for treatment of fetal dystocia due to goitre in a doe. Intas Polivet 15(2):349-350.

La Perle K.M.D. 2013. Sistema endócrino, p.682-686. In: Zachary J.F. \& McGavin M.D. (Eds), Bases da Patologia em Veterinária. 5a ed. Elsevier, Rio de Janeiro.

Levander O.A. \& Whanger P.D. 1996. Deliberations and evaluations of the approaches, endpoints and paradigms for selenium and iodine dietary recommendations. J. Nutr. 126(Suppl.9):2427-2434. http://dx.doi. org/10.1093/jn/126.suppl_9.2427S. PMid:8811808.

Macêdo J.T.S.A., Lucena R.B., Giaretta P.R., Kommers G.D., Fighera R.A., Irigoyen L.F. \& Barros C.S.L. 2011. Defeitos congênitos em bovinos na região central 
do Rio Grande do Sul. Pesq. Vet. Bras. 31(4):297-306. http://dx.doi. org/10.1590/S0100-736X2011000400005.

Marcolongo-Pereira C., Schild A.L., Soares M.P., Vargas Junior S.F. \& RietCorrea F. 2010. Defeitos congênitos diagnosticados em ruminantes na região sul do Rio Grande do Sul. Pesq. Vet. Bras. 30(10):816-826. http:// dx.doi.org/10.1590/S0100-736X2010001000003.

Martins E.0.1946. Bócio congênito em cabritos. Revta Faculdade Med. Vet. USP 3(3):123-126. http://dx.doi.org/10.11606/issn.2318-5066.v3i3p123-126.

Mohan Reddi N. \& Rajan A. 1986. Reproductive behaviour and semen characteristics in experimental hypothyroidism in goats. Theriogenology 25(2):263-274. http://dx.doi.org/10.1016/0093-691X(86)90061-0. PMid:16726117.

Oluwole O.A., Bartlewski P.M. \& Hahnel A. 2013. Relationships of serum thyroid hormones and follicle-stimulating hormone concentrations to Sertoli cell differentiation during the first wave of spermatogenesis in euthyroid ram lambs. Reprod. Biol. 13(2):150-160. http://dx.doi.org/10.1016/j. repbio.2013.04.001. PMid:23719121.

Ong C.B., Herdt T.H. \& Fitzgerald S.D. 2014. Hiperplastic goiter in two adult dairy cow. J. Vet. Diagn. Invest. 26(6):810-814. http://dx.doi. org/10.1177/1040638714554441. PMid:25292195.

Panziera W., Kowalski A.P., Galiza G.J.N., Bianchi R.M., Espíndola J.P., Cardoso M.M., Vargas A.C. \& Fighera R.A. 2014. Bócio congênito em caprinos no noroeste do Rio Grande do Sul, Brasil. Ciência Rural 44(12):2217-2220. http://dx.doi.org/10.1590/0103-8478cr20140413.

Paulíková I., Kovác G., Bíres J., Paulík S., Seidel H. \& Nagy O. 2002. Iodine toxicity in ruminants. Veterinární Medicína 47(12):343-350. http://dx.doi. org/10.17221/5845-VETMED.

Pavarini S.P., Sonne L., Antoniassi N.A.B., Santos A.S., Pescador C.A., Corbellini L.G. \& Driemeier D. 2008. Anomalias congênitas em fetos bovinos abortados no sul do Brasil. Pesq. Vet. Bras. 28(3):149-154.

Peixoto P.V., Malafaia P., Miranda L.V., Canella C.F.C., Canella Filho C.F.C. \& Vilas Boas F.V. 2003. Eficiência reprodutiva de matrizes bovinas de corte submetidas a três diferentes tipos de suplementação mineral. Pesq. Vet. Bras. 23(3):125-130. http://dx.doi.org/10.1590/S0100-736X2003000300005.

Peixoto P.V., Malafaia P., Barbosa J.D. \& Tokarnia C.H. 2005. Princípios de suplementação mineral em ruminantes. Pesq. Vet. Bras. 25(3):195-200. http://dx.doi.org/10.1590/S0100-736X2005000300011.

Pezzuti I.L., Lima P.P. \& Dias V.M.A. 2009. Hipotireoidismo congênito: perfil clínico dos recém-nascidos identificados pelo programa de triagem neonatal de Minas Gerais. J. Pediat. 85(1):72-79.

Radostits O.M., Gay C.C., Blood D.C. \& Hinchcliff K.W. 2002. Doenças causadas pela herança de caracteres indesejáveis, p.1562. In: Ibid. (Eds), Clínica Veterinária: um tratado de doenças dos bovinos, ovinos, suínos, caprinos e equinos. 9aㅡ ed. Guanabara Koogan, Rio de Janeiro.

Randhawa C.S., Randhawa S.S., Randhawa S.S. \& Dua K. 2014. Studies on the prevalence and diagnosis of subclinical iodine deficiency in buffaloes (Bubalus bubalis). Buffalo Bull. 33(2):192-198.

Riet-Correa F. 2007. Carências minerais, p.231. In: Riet-Correa F., Schild A.L., Lemos A.R.R. \& Borges J.R.J. (Eds), Doenças de Ruminantes e Equídeos. $3^{\text {a }}$ ed. Vol. 2. Palotti, Santa Maria.
Robbins J., Van Zyl A. \& Van der Walt K. 1966. Abnormal thyroglobulin in congenital goiter of cattle. Endocrinology 78(6):1213-1223. http://dx.doi. org/10.1210/endo-78-6-1213. PMid:4958570.

Rosol T.J. \& Gröne A. 2016. Endocrine glands, p.269-357. In: Maxie G. (Ed.), Jubb, Kennedy and Palmer's Pathology of Domestic Animals. 6 ${ }^{\underline{a}}$ ed. Vol. 3. Elsevier, San Diego. http://dx.doi.org/10.1016/B978-0-7020-53191.00014-1.

Seimiya Y., Ohshima K., Itoh H., Ogasawara N., Matsukida Y. \& Yuita K. 1991 Epidemiological and pathological studies on congenital diffuse hyperplastic goiter in calves. J. Vet. Med. Sci. 53(6):989-994. http://dx.doi.org/10.1292/ jvms.53.989. PMid:1790233.

Sinclair D.P. \& Andrews E.D. 1954. Goitre in new-born lambs. New Zealand Vet. J. 2(3):72-79. http://dx.doi.org/10.1080/00480169.1954.33157.

Singh R. \& Beigh S.A. 2013. Diseases of thyroid in animals and their management. p.233-240. In: Carreira R.P. (Ed), Insights from Veterinary Medicine. InTech, s.l. http://dx.doi.org/10.5772/55377.

Spicer L.J., Alonso J. \& Chamberlain C.S. 2001. Effects of thyroid hormones on bovine granulosa and thecal cell function in vitro: dependence on insulin and gonadotropins. J. Dairy Sci. 84(5):1069-1076. http://dx.doi. org/10.3168/jds.S0022-0302(01)74567-5. PMid:11384033.

Stukovsky R., Nemeth S. \& Podoba J. 1961. On the incidence of bovine and human goitre in Slovakia. Can. J. Comp. Med. Vet. Sci. 25(1):24-25. PMid:17649278.

Taylor S. 1954. Calcium is a goitrogen. J. Clin. Endocr. Metab. 14(11):14121422. http://dx.doi.org/10.1210/jcem-14-11-1412. PMid:13211780.

Thrift T.A., Bernal A., Lewis A.W., Neuendorff D.A., Willard C.C. \& Randel R.D. 1999a. Effects of induced hypothyroidism on weight gains, lactation, and reproductive performance of primiparous brahman cows. J. Anim. Sci. 77(7):1844-1850. http://dx.doi.org/10.2527/1999.7771844x PMid:10438032.

Thrift T.A., Bernal A., Lewis A.W., Neuendorff D.A., Willard C.C. \& Randel R.D. 1999b. Effects of induced hypothyroidism or hyperthyroidism on growth and reproductive performance of Brahman heifers. J. Anim. Sci. 77(7):18331843. http://dx.doi.org/10.2527/1999.7771833x. PMid:10438031.

Tokarnia C.H., Döbereiner J. \& Peixoto P.V. 2000. Deficiências minerais em animais de fazenda, principalmente bovinos em regime de campo. Pesq. Vet. Bras. 20(3):127-138. http://dx.doi.org/10.1590/S0100-736X2000000300007.

Tokarnia C.H., Peixoto P.V., Barbosa J.D., Brito M.F. \& Döbereiner J. 2010. Iodo, p.123-129. In: Ibid. (Eds), Deficiências Minerais em Animais de Produção. Helianthus, Rio de Janeiro.

Tokarnia C.H., Brito M.F., Barbosa J.D., Peixoto P.V. \& Döbereiner J. 2012. Plantas cianogênicas, p.443-444. In: Ibid. (Eds), Plantas Tóxicas do Brasil para Animais de Produção. $2^{\underline{a}}$ ed. Helianthus, Rio de Janeiro.

Vaisman M., Rosenthal D. \& Carvalho D.P. 2004. Enzimas envolvidas na organificação tireoidiana do iodo. Arqs Bras. Endocrinol. Metabol. 48(1):915. http://dx.doi.org/10.1590/S0004-27302004000100003.

Wither S.E. 1997. Congenital goiter in cattle. Can. Vet. J. 38(3):178. PMid:9056071

Wichtel J.J., Craigie A.L., Freeman D.A., Varela-Alvarez H. \& Williamson N.B. 1996. Effect of selenium and iodine supplementation on growth rate and on thyroid and somatotropic function in dairy calves at pasture. J. Dairy Sci. 79(10):1865-1872. http://dx.doi.org/10.3168/jds.S0022-0302(96)765542. PMid:8923257. 